\title{
How Cortisol May Inform Biden's Plan to Heal the Nation and Root out Systemic Racism
}

\author{
Ashley Andreou ${ }^{1}$ \\ ${ }^{1}$ Georgetown University School of Medicine \\ Keywords: racial violence, cortisol, chronic stress, anti-racism, public health, health justice \\ https://doi.org/10.52504/001c.18703
}

Georgetown Medical Review

Vol. 5, Issue 1, 2021

In Joe Biden's first address as president-elect, he promised his presidency would be a time for healing. ${ }^{1}$ Biden also stated he would do everything in his capacity to root out systemic racism and have the back of Black Americans, whose voter turnout played a large role in his victory. ${ }^{2}$ Although statements like these bring immense hope, they must be supported by clear policy changes.

In the first eight months of 2020, police have killed at least one Black American every week. ${ }^{3}$ Many Black Americans are understandably experiencing high levels of anxiety these days as these killings have not subsided and Black Lives Matter activism is met with state-sanctioned violence. On top of this, people of color are disproportionately being killed by SARS-CoV-2, the virus that causes COVID-19. If Black Americans had died at the same rate as White Americans, more than 21,000 of the former would still be alive today. ${ }^{4}$ On average, Black Americans are more likely than their white counterparts to be diagnosed with and die from infectious diseases, many types of cancer, heart attacks, lung disease, stroke, and diabetes-the same conditions that make them more susceptible to SARS-CoV-2. ${ }^{5}$ To effectively counteract systemic racism and help people in the US heal, policymakers need to counteract racial health disparities. In this endeavor, policymakers and healthcare professionals must evaluate the construction of Black Americans' environments.

While America today is an especially difficult environment, race-related stress has always been part of Black lives-a toxic, everyday pattern enabled and perpetuated by white people. This constant undercurrent of threat and danger, and the resulting chronic elevation of the notorious stress hormone cortisol, is a major driver of the racial health disparities. Cortisol, along with unequal access to healthy food, high levels of exposure to pollution, and unequal access to healthcare, have made the pandemic disproportionately deadly to communities of color.

Research has found that chronic experiences with race-related discrimination, elevating cortisol, strongly correlate with health disadvantage. ${ }^{6}$ A study at Duke University collected data from a campus-wide racist scandal found that Black students' cortisol levels were considerably elevated for weeks following the event. ${ }^{7}$ Studies show that racist experiences, like the reverberations from the killing of Breonna Taylor and George Floyd, elevate cortisol and initiate a 
series of unhealthy physiological responses, including elevated blood pressure, heart rate, and hypervigilance. ${ }^{6}$ Scientists and medical professionals know that it is deeply unhealthy to have long-term levels of high cortisol. ${ }^{8}$

Derrick Bell, the creator of critical race theory, reminds us that race is a social construction, socially rather than biologically or genetically constructed. ${ }^{9}$ Social constructions underly society and establish the environments in which we exist. Due to social constructions, America today is not equally stressful for all groups of people. Given this, it is unsurprising that the deleterious health effects of stress show similar disparities. The litany of racial health disparities we hear about must be reframed as an up-stream issue that is actively created and, thus, one that can be actively changed.

\section{Characterizing Race-Related Stress}

Past approaches to addressing racial health disparities have been myopic, as policymakers have focused on remedying social determinants of health and largely ignored race-related trauma and stress. ${ }^{10}$ Race-related stressors can come from racist policies, such as requiring cash bail, or experiences, like racial profiling or police brutality. ${ }^{11}$ Racist policies can cause physical and psychosocial stress and are characterized by the discriminatory enforcement of policies that disproportionately affect communities of color. ${ }^{12}$ The stress of losing a parent or child to the carceral system. The stress of being in the Medicaid coverage gap and avoiding the hospital at all costs. The stress of having to work when you can barely get out of bed because there is no paid sick leave at your job. The stress of working three jobs because the minimum wage is not a livable wage. The stress of letting your child walk home from school and knowing there are too many guns in your community. The stress of not being able to afford healthy food and then becoming more stressed out when the weight accumulates. The stress of being irreparably stressed and not having access to mental health resources you need and finding other ways to medicate. The stress of being pulled over and not knowing if you will leave the incident alive. The stress of walking down the street and knowing people are watching you and discerning how "suspicious" you look. The stress of seeing your community go up in flames and tear gas because some people refuse to recognize your humanity. The stress of white people constantly asking you to display your pain for them to understand. Again, this is not a homogenous illustration. The applicability of these stressors is dependent on factors like the strength of one's identity, income, geographic location, and residential segregation. One could read this list and think that some or none of these policies affect them, regardless of their skin color. The point is not to paint one person's or community's vignette, rather, it is to expound what research shows regarding the racially disparate enforcement of the above policies. ${ }^{13}$ 


\section{Understanding How Race-Related Stress Can Inform Change}

In Ibram X. Kendi's most recent book, How to be an Anti-Racist, he makes the point of urging readers to avoid using the term, "systemic racism." $\mathrm{He}$ states that it reduces racism to the abstract and, in turn, hobbles our capacity to create counteractive change. ${ }^{11}$ Race-related stress is one, powerful part of systemic racism, yet it is possible to address. The way some police officers react to Black Americans in high-stress situations has demonstrated that racism is deeply ingrained into many people's psyches. However, policies and protocols can check harmful behaviors and reduce the potential harm. In addition, the government, education system, and the media should be utilized to counteract, not feed, racial biases that underpin the treatment of Black Americans. Furthermore, culturally informed mental health resources need to be expanded to help give individuals and communities the tools to cope with race-related trauma and chronic stress. ${ }^{14}$ Defunding the police could allow for more money to be allotted by federal and state health authorities for mental health resources that focus on race-related trauma and stress.

Bottom Line: Over the past few months, many Black Americans have experienced multifactorial, chronic stress. Therefore, the best proposals to address racial health disparities will not only address conventional issues like access to healthcare, environmental health, and nutritional food but also the stressful everyday experiences of Black Americans. 


\section{REFERENCES}

1. Feiner L. Read Joe Biden's first speech as president-elect. CNBC News. November 7, 2020.

2. Johnson M. Biden gives shoutout to Black Americans in victory speech: "You always have my back, and I'll have yours." The Hill. November 7, 2020.

3. Police in the U.S. killed 164 Black people in the first 8 months of 2020. CBS News. December 17, 2020.

4. APM Research Lab. The Color of Coronavirus: COVID-19 Deaths by Race and Ethnicity in the U.S.November 12, 2020.

5. Weinstein JN, Geller A, Negussie Y, Baciu A, National Academies of Sciences Engineering and Medicine (U.S.). Committee on Community-Based Solutions to Promote Health Equity in the United States,. Communities in Action: Pathways to Health Equity. The National Academies Press; 2017.

6. Mays VM, Cochran SD, Barnes NW. Race, race-based discrimination, and health outcomes among African Americans. Annu Rev Psychol. 2007;58:201-225. doi:10.1146/ annurev.psych. 57.102904 .190212

7. Richman LS, Jonassaint C. The effects of race-related stress on cortisol reactivity in the laboratory: implications of the Duke lacrosse scandal. Ann Behav Med. 2008;35(1):105-110. doi:10.1007/s12160-007-9013-8

8. Stress Effects on the Body. American Psychological Association.

9. Willis AI. Critical Race Theory. In: Street BV, May S, eds. Literacies and Language Education. Springer International Publishing; 2017:17-29.

10. CDC Programs Addressing Social Determinants of Health.

11. Kendi IX. How to Be an Antiracist. 1st ed. One World; 2019.

12. Anderson KF. Diagnosing Discrimination: Stress from Perceived Racism and the Mental and Physical Health Effects*. Sociological Inquiry. 2013;83(1):55-81. doi:10.1111/ j.1475-682X.2012.00433.x

13. Gee GC, Ford CL. Structural Racism and Health Inequities: Old Issues, New Directions. $D u$ Bois Rev. 2011;8(1):115-132. doi:10.1017/S1742058X11000130

14. Motley R, Banks A. Black Males, Trauma, and Mental Health Service Use: A Systematic Review. Perspect Soc Work (Houst). 2018;14(1):4-19. 